\title{
The effect of epinephrine on tonic immobility (animal hypnosis) in chickens
}

\author{
RICHARD W. THOMPSON, ROBERT SCUDERI, and JAMES BOREN \\ Western Washington State College, Bellingham, Washington 98225
}

\begin{abstract}
To establish a dose-response relationship between epinephrine and tonic immobility (TI) in chickens, six groups of 10 cockerel chicks were given no injection, IP injection with saline, or injection with .125, $.25, .5$, or $1.0 \mathrm{mg} / \mathrm{kg}$ of epinephrine prior to three tests for duration of TI. Results indicated that TI was an increasing function of epinephrine dosage.
\end{abstract}

Tonic immobility (TI) or animal hypnosis has been observed in a wide variety of animals but has been most frequently investigated in chickens. Tonic immobility, which is typically elicited by restraint or sudden inversion, has been hypothesized to be a result of intense fear (Ratner, 1967). Several experiments have attempted to isolate the physiological mechanisms involved in this response. For example, Braud and Ginsburg (1973) have found that TI duration is increased by injections of epinephrine. The experiment to be reported here provides a dose-response curve for epinephrine and TI in chickens.

\section{METHOD}

\section{Subjects}

The subjects were 60 cockerel $\mathrm{H} \& \mathrm{~N}$ White Leghorn chicks obtained from a local hatchery at 1 day of age. The birds were maintained in a commercial brooder with food and water constantly available. The birds were exposed to $13 \frac{1}{2} \mathrm{~h}$ of artificial light each day.

\begin{abstract}
Apparatus and Procedure
To reduce the duration of TI, starting at the 8th day of age and continuing for 5 days, each bird was given three inductions of TI each day, the bird being permitted to stay down no longer than $30 \mathrm{sec}$. On the 13 th day of age, pairs of birds were randomly selected from the brooder, weighed, and assigned to one of six groups: control (C), no injection; saline (S), injected IP with $1 \mathrm{cc} / \mathrm{kg}$ of physiological saline; or one of four drug groups receiving $.125, .25, .5$, or $1.0 \mathrm{mg} / \mathrm{kg}$ of epinephrine in saline. All birds were placed in a holding box for $15 \mathrm{~min}$ prior to testing for TI.

Testing consisted of removing each bird from the box, holding it upright on a table for $15 \mathrm{sec}$, rapidly turning it on its side and holding it down for $15 \mathrm{sec}$, and gently releasing it. Tonic immobility was timed from release until the bird spontaneously righted itself or $180 \mathrm{sec}$ had elapsed. A bird failing to stay down at least $5 \mathrm{sec}$ was given a time of zero. Three such trials were given to each bird, the bird being placed back in the holding box between trials. The intertrial interval was no
\end{abstract}

James Boren is now at the Department of Psychology, State University of New York at Albany. This paper is part of a paper presented at the Rocky Mountain Psychological Association meeting in May 1974. Requests for reprints may be sent to Richard W. Thompson, Department of Psychology, Western Washington State College, Bellingham, Washington 98225. less than $15 \mathrm{sec}$, but could be as long as $195 \mathrm{sec}$. Duration of TI was timed with a stopwatch.

\section{RESULTS AND DISCUSSION}

Examination of the data revealed no consistent changes across trials for any group, so the mean duration of TI for the three trials for each bird was used for analysis. The mean duration of TI for each group is presented in Figure 1. Analysis of variance of these data support what is apparent in the figure; duration of TI increased with the highest dosages of epinephrine $[F(5,54)=4.03, p<.01]$. Further analysis with Duncan's multiple-range tests indicated that both the $.5-\mathrm{mg} / \mathrm{kg}$ and the $1.0-\mathrm{mg} / \mathrm{kg}$ groups differed significantly from the noninjected control group and the $.5-\mathrm{mg} / \mathrm{kg}$ group differed significantly from the saline group (all ps $<.05$ ).

These data are consistent with those of Braud and Ginsburg (1973), but it should be pointed out that

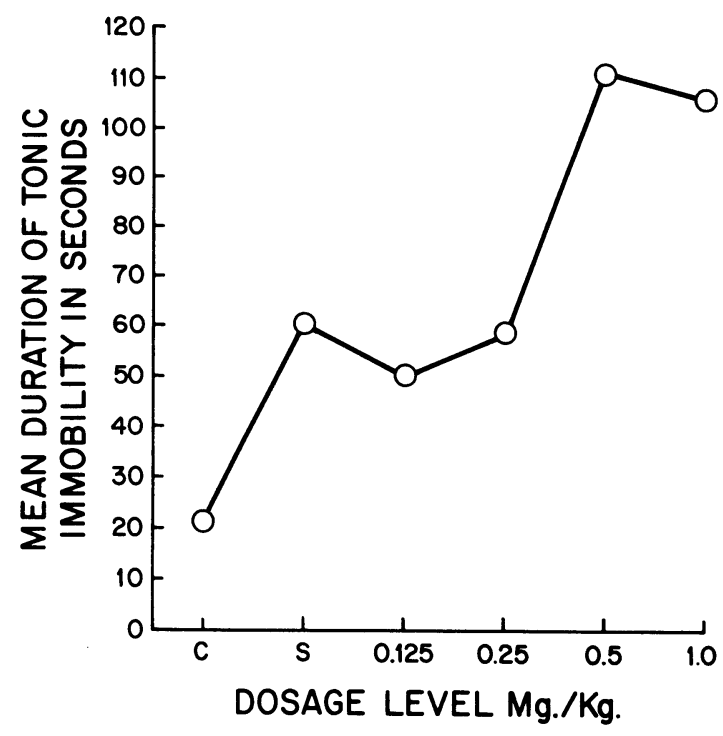

Figure 1. Dose-response curve for epinephrine and tonic immobility in seconds. $C$ is the noninjected and $S$ is the salineinjected control group. 
they injected their birds subcutaneously and that they obtained their greatest effect $60 \mathrm{~min}$ after injection. The data provide further support for the fear hypotheses for TI.

\section{REFERENCES}

Braud, W. G.. \& Ginsburg, R. J. Effect of administration of adrenalin on immobility reaction in domestic fowl. Journal of Comparative and Physiological Psychology, 1973, 83, 124-127.

RATNER, S. Comparative aspects of hypnosis. In Gordon, J. E. (Ed.), Handbook of clinical and experimental hypnosis. New York: Macmillan, 1967.

(Received for publication January 12, 1977.) 